\title{
BUCKWHEAT, SUSTAINABLE INGREDIENT FOR BREAD BAKING: RHEOLOGICAL AND TECHNOLOGICAL INVESTIGATION
}

\author{
Mihai, OGNEAN ${ }^{1}$, Claudia Felicia, OGNEAN ${ }^{2}$, Didina, DAMIAN ${ }^{2}$ \\ ${ }^{1}$ Lucian Blaga University, Sibiu, Romania, mihai.ognean@ulbsibiu.ro \\ ${ }^{2}$ Technological High School, Sebes, Romania
}

\begin{abstract}
Buckwheat is a plant with high sustainable potential. The sustainable agronomical potential is demonstrated by a very long and continuously cultivation, especially in Asia and Eastern Europe. Buckwheat could be found in a high number of traditional recipes and contribute to the health of populations through theirs high content of fibres, high quality proteins and many functional ingredients as antioxidants. In Romania buckwheat it is consumed in reduced quantity but could be used to formulate some functional food which could contribute to the population's health and baking industry sustainability. We investigated the effects of replacement of wheat flour with $10 \%, 20 \%$ and $30 \%$ buckwheat flour. We evaluated the rheology and bread characteristics. At low level of wheat flour replacement positive effects could be observed but at 30\% replacement of wheat flour the dough rheology and bread characteristics were severely affected. The taste and specific volume were most affected. We consider that buckwheat has a real potential to be use in the formulation of functional food and is a sustainable ingredient for bread baking.
\end{abstract}

\section{INTRODUCTION}

Buckwheat is a pseudocereal, originated from China but cultivated worldwide today. Two main species are cultivated, common buckwheat (Fagopyrum esculentum) and tartary buckwheat (Fagopyrum tataricum). Its belong to the family Polygonaceae, the genus Fagopyrum [1]. The seeds of the plants were consumed for long time in history and many traditional foods are based on that plant but in time the cultivation and consumption are less, under the pressure of more appealing plants as maize and wheat. Despite of reducing the popularity, buckwheat has important sustainable aspects as economic, agronomic and nutritional. The cultivation of buckwheat has some advantages as: quick cover (the plants quickly cover the soil and act as a weed suppressor); grows very well in poor soils; quick regrow after mowing; soil conditioner and important sources of nectar [2,3], among the highest yield of honey [1]. The buckwheat plants need only half of the water consumed by soy plant. Buckwheat could be a second crop because of short time growing season [4]. These aspects contribute at the sustainability of buckwheat but other aspects are contributing also its sustainability. Other aspect of buckwheat cultivation is its contribution to the management of insects [5].

Some traditional food products based on buckwheat are consumed in China, Japan, Russia, Japan, Poland. Such traditional food products are noodle, soba, pancake, porridge, unleavened bread and jelly noodle [1]. The nutritional quality of buckwheat was appreciated for long time. The composition of buckwheat flour seem to be similar to whole wheat: ash $2.4 \%$; protein $10.5 \%$, fat $2.8 \%$, crude fibre $2.6 \%$ and starch $70.2 \%$ [6]. Buckwheat is rich in $\mathrm{Mg}, \mathrm{Se}, \mathrm{Fe}, \mathrm{K}, \mathrm{Ca}, \mathrm{Cu}, \mathrm{Mn}$, $\mathrm{Zn}$, particularly the content of $\mathrm{Mg}$ is 11 to 13 times higher, $\mathrm{Fe}$
3 to 4 times, K 3 times and tartary buckwheat flour contain Se, $0.43 \mathrm{mg}$ per $\mathrm{kg}$. Other study [7] showed that the fibre content in buckwheat flour is $6.5 \%$ while in wheat flour is only $2.4 \%$. The soluble dietary fibres represent $0.5 \%$. The resistant starch represents 13.1 to $22.5 \%$. The biological value of protein from buckwheat is very high, 93, comparing with the biological value of proteins from wheat and soy, 63 and respectively 68 [1]. Buckwheat proteins could be used to complement other food protein. The limiting aminoacid in buckwheat proteins are threonine and methionine [1] while in wheat's proteins the limiting amino acid is lysine [8]. Still the digestibility oh buckwheat proteins are low because the presence of antinutritive compounds (trypsin inhibitors), high amount of tannins and dietary fibres [1]. Unsaturated fatty acids represent 75 to $80 \%$ of total fatty acids in buckwheat. Other important components are present in buckwheat and recommend it as functional food. Flavonoids are present in buckwheat in high amount. Flavonoids present are rutin, quercetin, quercitin, kaemferol, orientin/isoorientin, and vitexin/isovitexin, rutin are present in higher amount in tartary buckwheat [1]. The antioxidant activity of phenolic compounds was proved in vitro and in vivo and also the antiproliferative activity against human liver cancer cells [9]. Buckwheat showed the highest antioxidant activity among other pseudocereals [10].Tartary buckwheat has a higher content of flavonoids and also is bitterer than common buckwheat. The benefits of consuming tartary buckwheat is showed that people from mountainous region of China were buckwheat is consumed regularly have low occurrence of chronic diseases such as diabetes and hypertension [11]. Other important components are phytosterols, fagopyrins and cinnamic acids. The antiadipogenic effects of buckwheat extracts were proved [12].

Several studies already showed that buckwheat and tartaric 15 
buckwheat especially have therapeutic effects as: hypolipidemic and hypoglycaemic; reducing hypertension, obesity, constipation in human's mammary carcinogenesis, and reducing colon carcinogenesis at rat and cholesterol gallstones at hamster. Tartary buckwheat has better functional properties, probably related of tat the content of flavonoids are 67 times higher and rutin content is 93 times higher than others species of buckwheat [4].

Some researches focused on incorporation of pseudocereals in different food products, even in different types of bread, biscuits and cookies [13]. The aim of this research is to investigate how the incorporation of buckwheat flour, in different proportion, will affects the dough's properties and bread quality.

\section{MATERIALS AND METHODS}

In the experiments wheat flour was replaced with buckwheat flour in different proportions, $0 \%, 10 \%, 20 \%$ and $30 \%$. The effects of wheat flour replacement were evaluated rheological by farinographic test and technological by baking test.

We used for trials commercial groats buckwheat (SOLARIS) which were milled to form a fine flour with a disk mill (DLFU, Buhler). Commercial wheat white flour was used, moisture $11,2 \%$, wet gluten content $29.4 \%$, ash $0.63 \%$. Yeast and salt were commercial grade too.

Water absorption and physical characteristics of dough were determined using method ISO 5530-1:2013. For baking the dough was prepared with a lab mixing machine by mixing wheat flour or a mixture of wheat flour and buckwheat flour $(100 \%)$ with water (Farinographic determined), yeast $(3 \%)$ and salt $(1,8 \%)$ until a full developed dough. The dough was fermented for 1 hour and after that divided, shaped and placed in tins. The dough was proofed for $45 \mathrm{~min}$ at $30^{\circ} \mathrm{C}$ and after that baked at $220^{\circ} \mathrm{C}$ for $40 \mathrm{~min}$.

The specific volume was determined by rape seed displacement method. The elasticity of bread crumb was measured by height recovery of a crumb cylinder after his compression at half of height for 1 minute followed by 1 minute to recovery. The porosity of crumb was measured by differences between the volume of cylinder cut from the centre of bread crumb and the volume of compressed crumb cylinder, measured by oil displacement with a graduated cylinder. All experiments were made at least in duplicate.

The sensorial evaluations of breads were performed using a Romanian scheme with points considering the main aspects of bread: external appearance of bread - 3 points, crust appearance -3 point, crumb appearance -8 points, smell -3 point, taste 3 points, maximum score 20 points.

\section{RESULTS AND DISCUSSIONS}

One of the most important aspects of replacement of wheat flour with buckwheat flour is the higher water absorption level of the mixtures with buckwheat. In the Figure 1 are presented the results. The water absorptions increased from $63 \%$ in the control sample with no buckwheat flour addition to $78.8 \%$. The water absorption is directly related with the level of wheat flour replacement, a very good linear correlation was established $\left(R^{2}=0.974\right)$. To achieve the same consistency more water was needed as the level of wheat flour was higher. Buckwheat flour has a higher content of fibres which lead to a higher water absorptions.

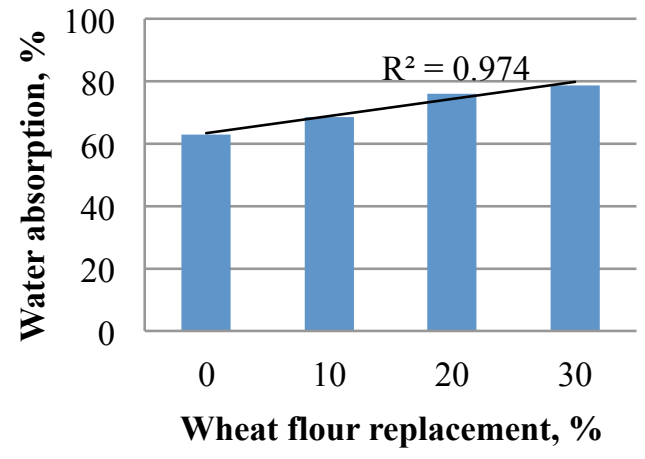

Figure 1. Water absorption of the mixture wheat flour: buckwheat flour

Physical characteristics of dough during mixing were evaluated with a Farinograph (Brabender). The results are presented in the Table 1.

Table 1. Rheological characteristics of dough during mixing at different level of replacement of wheat flour with buckwheat flour.

\begin{tabular}{|c|c|c|c|c|}
\hline $\begin{array}{r}\text { Wheat flour } \\
\text { replacement } \\
\text { Dough } \\
\text { characteristics }\end{array}$ & $\mathbf{0 \%}$ & $\mathbf{1 0 \%}$ & $\mathbf{2 0 \%}$ & $\mathbf{3 0 \%}$ \\
\hline Development time (min.) & 3 & 5 & 6 & 8 \\
\hline Stability (min.) & 1,5 & 6 & 5,5 & 4 \\
\hline Dough softening (B.U.) & 60 & 100 & 120 & 140 \\
\hline $\begin{array}{c}\text { Mixing Tolerance Index } \\
\text { (B.U.) }\end{array}$ & 40 & 0 & 0 & 20 \\
\hline
\end{tabular}

One of the most important aspects of the dough rheology is development time, the time needed to achieve the maximum the consistency of the dough. Development time increased from $3 \mathrm{~min}$ to $8 \mathrm{~min}$ when wheat flour was replaced with buckwheat flour. Similar behaviour was observed in other researches were added fibres competed with gluten for water and delay dough formation [15]. Similar effects were observed for the dough stability. The stability during mixing increased when wheat flour was replaced with buckwheat flour. The higher effect was observed at $10 \%$ displacement. When displacement of wheat flour increased the dough stability decreased but still remained higher than for control. The high level of fibres delayed gluten formation and dough development but also diluted the gluten content. Despite that development time and dough stability increased when buckwheat was added the dough become softer. Dough consistency decreased in time because of a sharp drop after the full development of dough. The drop was higher when the level of displacement was higher. These reveal that buckwheat flour alter the dough rheology despite that most of the characteristics were improved. The improvement of dough rheology was due the fibre present in buckwheat flour.

The effects of buckwheat flour on the quality parameters of bread are shown in Figure 2, Figure 3 and Figure 4. The effect on the specific volume is complex. At $10 \%$ replacement the specific volume of bread is higher than control but at higher level of substitution the specific volume decreased. The bread specific volume at 30\% substitution, the higher level tested, was $237 \mathrm{ml} / 100 \mathrm{~g}$. This value is acceptable for black and whole bread. The improvement of specific volume at $10 \%$ replacement of wheat flour could be explained by the softening effects of buckwheat flour on quite "short" dough. 
The substitution of wheat flour had a bad effect on the porosity of a crumb. The crumb porosity decreased with increasing level of wheat flour displacement in the bread recipe. The crumb structure and retaining of gas inside of dough was affected because dilution of gluten on one hand and negative effect of fibres contained in buckwheat flour on the other hand. The porosity decreased from $77 \%$ in control sample to $67 \%$ in brad with $30 \%$ buckwheat flour. Deterioration of bread crumb structure was more obvious and accentuated at high level of buckwheat flour addition.

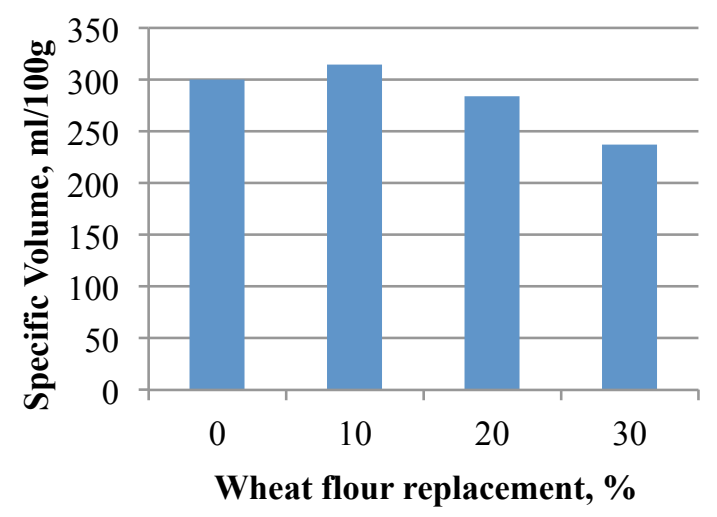

Figure 2. Specific volume of breads at different level of wheat flour substitution

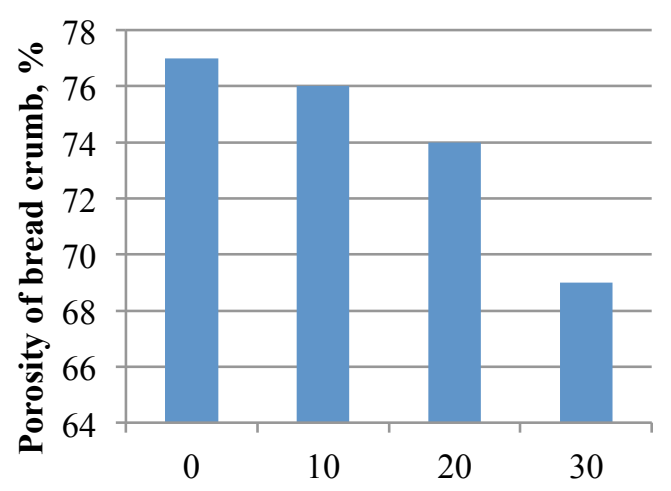

Wheat flour replacement, \%

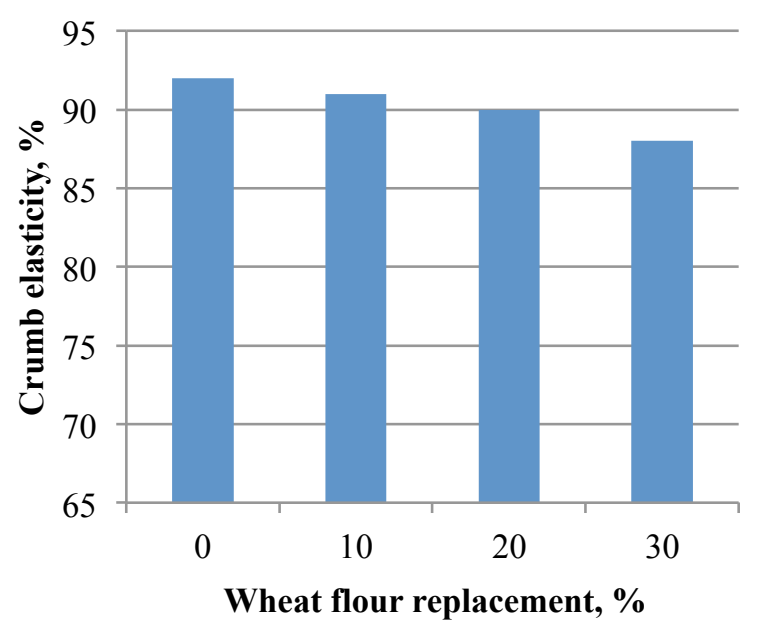

Figure 4. Elasticity of bread crumb at different level of wheat flour substitution

Crumb elasticity was affected by wheat flour displacement in similar way as in the case of crumb porosity. The elasticity decreased from $92 \%$, in the case of control sample to $88 \%$ in bread with maximum substitution of wheat flour. The recovery of crumb wad more affected at highest level of substitution.

The sensorial properties of breads were affected by wheat flour substitution and reflect the effects of buckwheat flour on the rheological properties of dough and bread characteristics. The aspects of sectioned breads are presented in Figures 5.The scores of breads are presented in Figure 6. At $10 \%$ and $20 \%$ buckwheat addition the scores of bread increases with several points comparing with control sample. The external appearance was affected by buckwheat flour but the taste and smell of bread was improved. For the control sample the taste and smell specific for yeast and flour was strong but when buckwheat flour was added at 10 and $20 \%$ these were improved. The substitution of wheat flour with $30 \%$ buckwheat flour had the worst effect, all characteristics evaluated suffered.

Figure 3. Porosity of bread crumbs at different level of wheat flour substitution

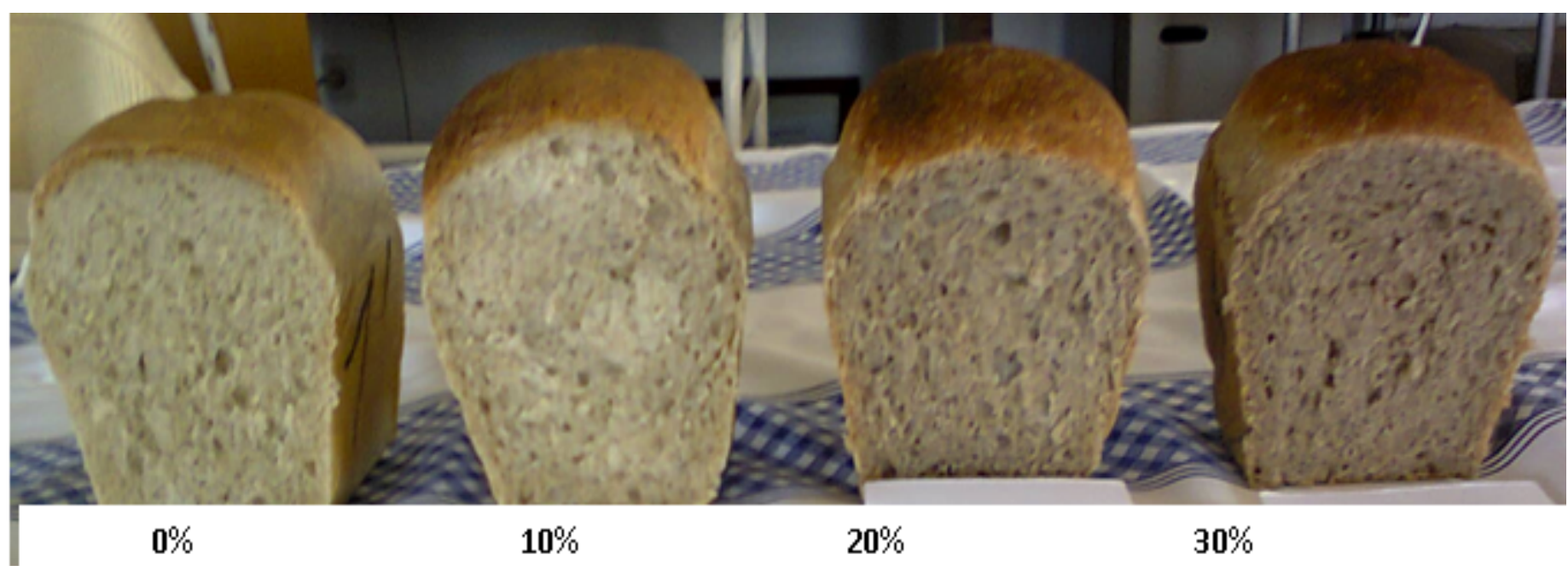

Figure 5. Aspects of bread prepared with buckwheat flour 


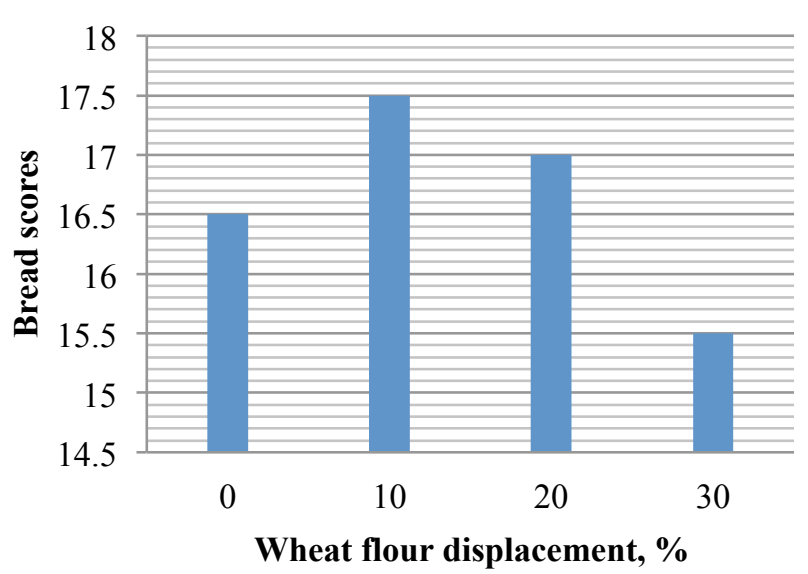

Figure 6. Scores of bread crumb at different level of wheat flour substitution

At a level of $30 \%$ buckwheat flour in bread recipe the external and internal appearance were affected, an darkening effect reduced the scores, and smell and taste were affected too, the taste became particularly bitter and specific for buckwheat. This aspect was determined for low scores because this taste and smell it is not familiar for regular bread available in the Romanian stores. As could be observed in the Figure 6, the crumb and crust colour became darker with the level of wheat flour substitution. The internal structure of crumb became coarser, with irregular pores.

\section{CONCLUSIONS}

Wheat flour replacement with buckwheat flour had some effects on the dough rheology as increased water absorption and development time of the dough, as the dough stability and dough softening. The water absorption, development time and stability increases probably due the fibre high content of buckwheat. Fibres absorb more water than gluten proteins and compete with gluten protein for water. The dough softening increases too because of gluten dilution by wheat flour replacement. When wheat flour was replaced with buckwheat flour the dough become softer, the consistency decreased. The bread characteristics were affected too through buckwheat addition to bread recipe. At 10 and $20 \%$ wheat flour substitution the effect was small and a small improvement was observed but at maximum level of substation studied the effect was high and the bred characteristics were deteriorated. Specific volume, crumb porosity, smell and taste were most affected.

Buckwheat flour could be used with good results for replacement of wheat flour in bread recipe. At 10 and $20 \%$ substitution no problems occurred but at $30 \%$ substitution the limits of acceptability were reached. Probably at level of substitution higher than $30 \%$ the consumers will reject the products.

We consider that the substitution of wheat flour in bread formulation with $30 \%$ buckwheat flour it is possible with no efforts from bakers but higher level of substitution need more action to improve the bread characteristics. The use of buckwheat flour in bakeries could contribute at the sustainability of baking industries in several ways: buckwheat plant could be cultivated on poor soils with low cost, it is no need for any changes in the bakeries and the final products will contribute to the health of population through the benefits of fibres, high quality proteins and antioxidant activity.

\section{REFERENCES}

1. Cai Y.Z., Corke H. and Li W.D., Buckwheat, in Encyclopedia of Grain Science, $1^{\text {st }}$ Edition, ed. Colin W., Academic Press, (2004).

2. ***, Buckwheat, Sustainable Agriculture Research \& Education (SARE), https://www.sare.org/LearningCenter/Books/Managing-Cover-Crops-Profitably-3rdEdition/Text-Version/Nonlegume-CoverCrops/Buckwheat, (accessed August 2017).

3. Tolaini V., Del Fiore A., Nobili C., Presenti O., De Rossi P., Procacci S., Vitali F. and Brunori A., Exploitation of Tartary buckwheat as sustainable ingredient for healthy foods production, Agriculture and Agricultural Science Procedia, 8, pp. 455-460, (2016).

4. Izydorczyk M.S., McMillan T., Bazin S., Kletke J., Dushnicky L. and Dexte, J., Canadian buckwheat: A unique, useful and under-utilized crop, Can. J. Plant Sci., 94, pp. 509-524, (2014.).

5. Tavares J., Wanga K.-H. and Hooks C. R.R., An evaluation of insectary plants for management of insect pests in a hydroponic cropping system, Biological Control, 91, pp. 1-9, (2015).

6. Qin P., Wang Q., Shan F., Hou Z. and Ren G., Nutritional composition and flavonoids content of flour from different buckwheat cultivars, International Journal of Food Science \& Technology, 45, pp. 951-958, (2010).

7. Bonafaccia G. and Fabjan N., Nutritional comparison of tartary buckwheat with common buckwheat and minor cereals, Zb. Bioteh. Fak. Univ. Ljublj. Kmet., 81 - 2, oktober 2003, (2003).

8. Kies C., and Fox H.M. Determination of the first-limiting amino acid of wheat and triticale grain for humans, Cereal Chem., 47, pp. 615, (1970).

9. Li F., Zhang X., Zheng S., Lu K., Zhao G. and Ming J., The composition, antioxidant and antiproliferative capacities of phenolic compounds extracted from tartary buckwheat bran [Fagopyrum tartaricum (L.) Gaerth], Journal of Functional Foods, 22, pp. 145-155, (2016).

10. Inglett G.E., Chen D. and Liu S.X., Antioxidant Activities of Selective Gluten Free Ancient Grains, Food and Nutrition Sciences, 6, pp. 612-621, (2015).

11. Zhu F., Chemical composition and health effects of Tartary buckwheat, Food Chemistry, 203, pp. 231-245, (2016).

12. Zhou Z., Ren, X., Wang F., Li J., Si X., Cao R., Yang R., Strappe P. and Blanchard C., High pressure processing manipulated buckwheat antioxidant activity, antiadipogenic properties and starch digestibility, Journal of Cereal Science, 66, pp. 31-36, (2015).

13. Shewry P.R. and Hey S.J., The contribution of wheat to human diet and health, Food and Energy Security, 4(3), pp. 178-202, (2015).

14. Janssen F., Pauly A., Rombouts I., , Jansens K.J.A., Deleu L.J., and Delcour J.A., Proteins of Amaranth (Amaranthus spp.), Buckwheat (Fagopyrum spp.), and Quinoa (Chenopodium spp.): A Food Science and Technology Perspective, Comprehensive Reviews in Food Science and Food Safety, Vol.16, pp. 39-58, (2017).

15. Ognean M., Ognean C.-F. and Darie N., Rheological effects of some natural fibers used in breadmaking, Acta Universitatis Cibiniensis Series E: Food Technology, Vol.14, No. 23, pp. 3-10, (2010). 